\title{
تأثير أسلوب ملء الحروف المفقودة على مهارةالكتابة لدى التلاميذ بحث تجريبي في المدرسة الثانوية عائشية بادنج
}

\author{
Allbert Gustinata \\ IAIN Bukittinggi \\ immawan.allbert@gmail.com \\ Ferki Ahmad Marlion \\ IAIN Batusangkar \\ Ferkialfateh92@gmail.com
}

\begin{abstract}
The purpose of this research is to find out the effect of using the method of filling in missing letters on the outcome of teaching writing skills in the seventh grade of Aishah Bading High School. The author uses an experimental research method with three data machines, i.e. observation guide, interview guide, exam questions, and research design in True Eksperimental Design, in the pretestposttest control group design. As for the result, it has the maximum results of teaching the skill of writing in the manner of filling in the missing letters 100 and the lowest results 60 . Then the author found that the result of $t_{-}(0)$ is greater than the result of $t_{-}(t)$, which is $36,3>79,3>31,2$. Therefore The imposition of nihilism is returnable and the imposition of reciprocity is acceptable, and it is intended to find the difference between the outcome of teaching the skill of writing by using the method of filling in the missing letters and without using them. The conclusion of this research is that the method of filling in the missing letters affects the outcome of teaching the skill of writing.

Keywords: Uslub Mal'i al Hurufal Mafqudah, Maharah al Kitabah, Ta'lim
\end{abstract}

$$
\begin{aligned}
& \text { ملخص } \\
& \text { الغرض من هذا البحث هو لمعرفة تأثير استعمال أسلوب ملء الحروف المفقودة على نتيجة تعليم }
\end{aligned}
$$

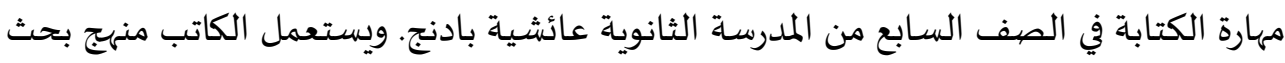

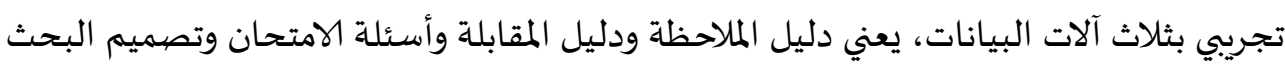

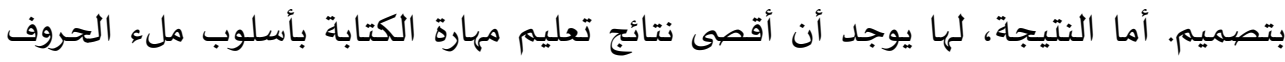

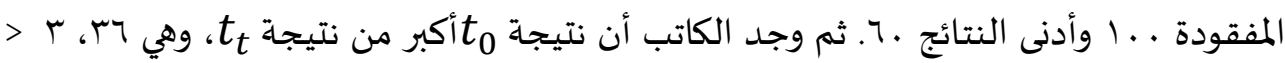




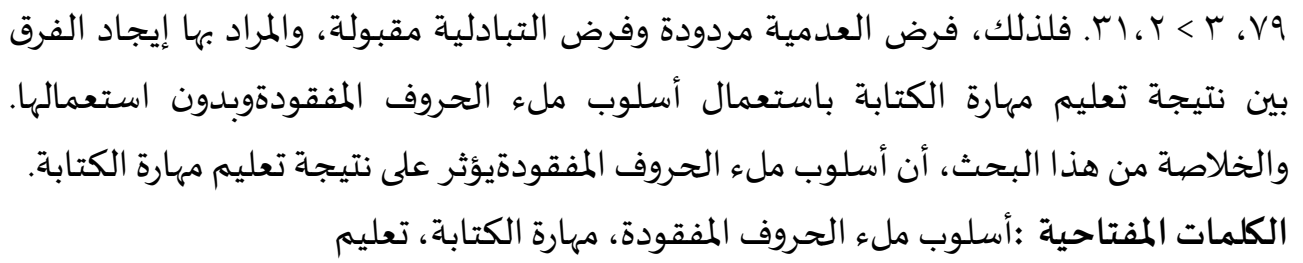

\begin{abstract}
Abstrak
Tujuan penelitian ini untuk mengetahui pengaruh strategi mengisi huruf yang hilang terhadap pembelajaran maharah kitabah pada kelas VII di MTs Aisyiyah Padang. penulis menggunakan metode penelitian study experiment (penelitian lapangan) dengan tiga langkah yakni: observasi, wawancara dan test serta design penelitian dengan design true exsprimental design dengan jenis pretest-posttest control group design. Adapun hasil dari penelitian ini memiliki nilai maksimal pada pembelajaran maharah kitabah dengan strategi mengisi huruf yang hilang, paling tinggi nilainya 100 paling rendah nilainya 60 kemudian penulis telah mendapatkan nilai to lebih besar dari nilai tt yaitu : $2,31<3,79>3,36$. Oleh karena itu hipotesis yang lama ditolak dan hipotesis terbaru di terima, maksudnya adalah menemukan perbedaan antara hasil nilai pembelajaran maharah kitabah dengan menggunakan strategi mengisi huruf yang hilang dan tanpa menggunakan strategi tersebut. Dan kesimpulan dari penelitian ini, bahwasanya strategi mengisi huruf yang hilang berpengaruh terhadap hasil pembelajaran maharah kitabah.
\end{abstract}

Kata Kunci : Uslub Mal'i al Huruf al Mafqudah, Maharah al Kitabah, Ta'lim

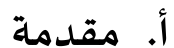

اللغة في شكلها الملفوظ والمكتوب أداة عجيبة تنتقل بها الأشياء التي تقع عليها حواسنا إلى

أذهاننا. إن للفة وظيفة كبرى في حياة الفرد، فهي التي يتخذها المرء للتعبير عما يجيش في نفسـا

من إحسـاسـات وأفكار، وهي وسيلة لاتصال المرء بغيره، واللغة تعين على ضبط التفكير ودقتاه،

لأن التفكير لايمكن أن يتم دون استخدام الألفاظ الدالة على معان محددة. ومن أغراض اللغة

أها وسيلة لنشر الثقافة بين أفرد الأمة ونقلها من السلف إلى الخلف، ولذا فقد كانت الأداة

الأولى الممتازة للتعليم، وباللغة يستطيع أن ينتقل المعرفة من فرد إلى آخر ومن جيل إلى

$$
\text { جيل.(الركابي, 1997) }
$$

كانت المهارة اللغوية في اللغة العربية أربعة مهارات وهي مهارة الإستماع ومهارة الكلام

ومهارة القراءة ومهارة الكتاباة(F. A. Marlion, 2019).وهذه المهارات أعمال مرتبة أو منظماة في

$$
\text { عملية تعليم الغة العربية. }
$$

كانت المدرسة الثانوية عائشية بادنج احدى من المدارس الثانوية في بادنج، قابل الكاتب

مدرس اللغة العربية في هذه المدرسـة، فوجد الكاتب أن التلاميذ لم يستطيعوا أن يكتبوا 
الحروف الهجائية التي مناسبة بقواعد اللغة العربية وله يستطعوا أن يقيدوا حرفا واحدا إلى

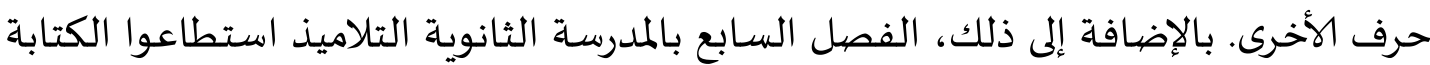
جيدا. لأنهم درسوا تلك المادة في المدرسة الإبتدائية، بل أن أهداف بهاف مهارة الكتابةهييستطيع التلاميذ أن يكتبوا الحروف الهجائية الصحيحة.

عند عملية التعليم، كان المدرس يستخدم أسلوب التعليم في اتصال المادة الدراسيةغير ابتكاري ويستخدم الطرق التقليدية. وهذه الطرق له يورّط التلاميذ بالفعالي، ولكن هذه الطريقة يركّز بالمدرس حتى يظهر التعليم سائما الذي له التأثير على نتيجة تعليم التلاميذحتى ئه لم يشترك التلاميذ عملية التعليم جيدا. سوى ذلك، كان التلاميذ عدم فعلي في إلقاء السؤال عن المادة الدراسية، حتى لم يبلغ أهداف التعليم الذي يلقى المدرس أثناء التعليم. ثم طبقات

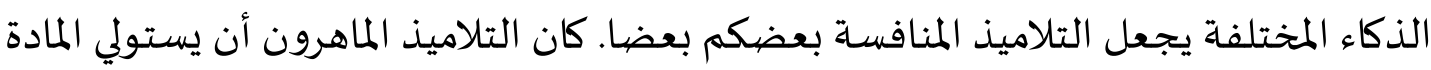
الدراسية، وبالعكس كان التلاميذ سائمون أثناء التعليم. و لذلك يحتاج إلى أسلوب التعليم الذي يشترك لكل التلاميذ أثناء التعليم. أسلوب مله الحروف المفقودة هو أسلوب الذي يستعمل التلاميذ الإبتدائية في تعليم

$$
\text { مهارة الكتابة ليمتحن التلاميذ في كتابة الحروف الهجائية. }
$$

أما الأهداف من أسلوب ملء الحروف المفقودة هي تمارس الكتابة لدى التلاميذ في كتابة الحروف الهجائية الصحيحة. وملء الحروف المفقودة مطابق تستعمل في تعليم الكتابة لأن هذه الإستراتيجية لسهل التلاميذ في كتابة الحروف الهجائية.

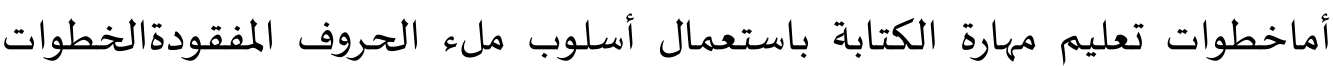

ا. المعلم يكتب جملة كاملة مرارا وتكرارا إلى أسفل على قطعة من الورق. وسـادة كل الجملة

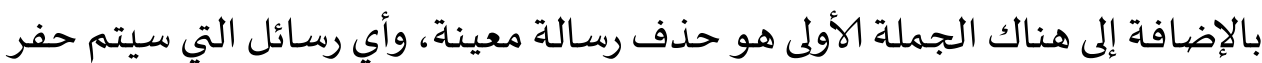

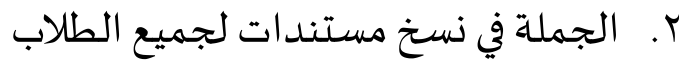

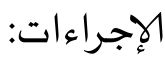

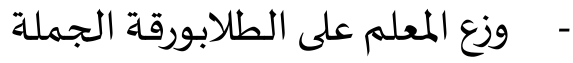

- طلب المعلم من بعض الطلاب قراءة الجملة الأولى تبديلا

- - جميع الطلاب بإكمال الحروف المفقودة ويهتم أو أولى الجملة

- انتهى اللتلاميذ ، معلم يدعوهم تحليل أعملههم بدلالة طريقات لتكمل في السبورة.

مثل: الكلمة لتدريبات التلاميذ الكتابة الحروف(Asrori, 2010) 
تعليم مهارة الكتابة هو إحدى مهارات اللغة العربية الأربعة في المدرسة الثانوية عائشية. ولكن هذا الدرس يعتقد باحدى الدرس سائما الذي يسبب على منخفض نتيجة تعليم التلاميذ(F. Marlion, 2017).وبعد ما يعمل الكاتبالإختبار القبليأن نتيجة تعليم مهارة الكتابة لدى التلاميذ منخفض. وعرف الكاتب هذا الحال من نتائج التلاميذ بعد امتحان مهارة الكتابة،

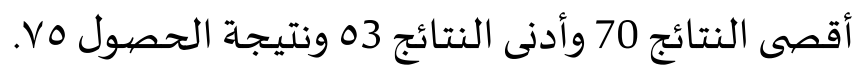

أما أهداف تعليم مهارة الكتابة فهي تستطيع التلاميذكتابةووصيلة الكلمات اللغة العربية بالصحيحاة. فلذلك لتبلغ هذه الأهداف، يحتاج إلى الأساليب التي تناسب لمهارة الكتابة، منها: أسلوب ملء الحروف المفقودة. وقال إمام أسراري أنه يناسب للمبتدئين في اللغة العربية. لأن هذا الأسلوب مناسب لفصل السـابع في المدرسـة الثانوية لأن موجود الفائد ليستطيع التلميذ كتابة الحروف الصحيحة.فلذلك يريد الكاتب أن يجرب هذا الأسلوب في مهارة الكتابة تحت الموضوع: "تأثير أسلوب ملء الحروف المفقودة على مهارةالكتابة لدى التلاميذ بحث تجريبي في المدرسة الثانوية عائشياة بادنج".

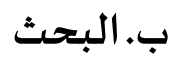

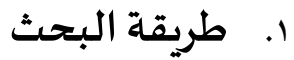

نوع البحث الذي يستعمله الباحث في هذه الرسالة فهي البحث الميداني الكيفي (field research) لتكميلال المعلومات. أما معلومات البحث هي توجد من نتائج الملاحظة التي تعتمد بمشكلات البحث وأهدافه التي كتبها الباحث في هذه الرسالة عن الكفاءة الأسـاسية في تعليم اللغة العربية في المدرسة الثانوية عائشية بادنج. أما مجتمع البحث في هذا البحث فهو كل تلميذ في المدرسة الثانوية عائشية بادية بادنج الذين يتكوّن من الصف السـابع إلى الصف التاسع بعددهم 95التلاميذ.

\begin{tabular}{|c|c|c|}
\hline التلاميذ الت & العناصر & 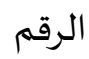 \\
\hline 18 & التلاميذ في الفصل السـابع 1 & 1 \\
\hline 18 & التلاميذ في الفصل السـابع r & r \\
\hline 29 & التلاميذ في الفصل الثامن & r \\
\hline 28 & التلاميذ في الفصل التاسع & $\varepsilon$ \\
\hline
\end{tabular}

وأما عينة البحث، فيأخذ الكاتب التلاميذ في الصف الصف السـابع من المدرسـة الثانوية عائشيةبادنج بعددهم 36 تلاميذ. يأخذ الكاتب فصلين، وهما فصل أ (المجموعاة التجريبية experiment) بعددها 18التلاميذ ، وفصل ب (المجموعاة 
one بعدابطاب/contro) الضدها 18 التلاميذ. ويأخذ الكاتب عينة تجريبية باستعمال grouppretest-posttest

\begin{tabular}{|r|r|r|}
\hline الرقم العناصر & \\
\hline 18 & التلاميذ & \\
\hline 18 & التلاميذ في الفصل السابـ في الفصل السابع r & \\
\hline
\end{tabular}

أما آلة لجمع البيات المستعملة في بحث هذه الرسالة كما يأتي: أ.) المقابلة : هويقابل الكاتب مدرس اللغة العربية في المدرسة الثانوية عائشية بادنج بتحليل المشكلة المتعلقة بالبحث التي بحث عنه الكاتب في خطة الرسالة العلمية

$$
\text { باستعمال دليلا المقابلة }
$$

ب.) الامتحان : يقوم الكاتب بالامتحان على التلاميذ في المدرسـة الثانوية عائشية بادنج لمعرفة نتيجتهم في تعليم مهارة الكتابة بعد ما يستعمل الكاتب بأسلوب ملء الحرف المفقود باستعمال أسئلة الإمتحان

يستعمل الكاتب تصحيح البيانات وثقاتهابأن يختبر الكاتب البيانات باستخدام المراجع أو النظريّات التي يتعلق بهذا البحث.وجد الكاتب البيانات فتحليل ببيان عدد لمعرفة تأثير أسلوب ملء الحرف المفقود على تعليم مهارة الكتابة بحث (nominal) تجريبي في المدرساة الثانوية عائشية بادنج

أ) أسلوب ملء الحروف المفقودة على مهارةالكتابة لدى التلاميذ

الكتابة هي الفن اللغوي الرابع، فيقصد بها التعبير الكتابي الذي نسميه نحن عادة بالتعبير التحريري. والإملاء والخط فيمكن تسميتها بالمهارات الكتاباة المساعدة، أو مهارات التحرير العربي وهي الرسم السليم للحروف والكلمات والجمل منفصلة و متصلة.(شحاتة, 1997) وعلامات الترقيم، والخط الواضح الجميل.وهذا الفن الذي هو الكتابة يجب أيتخذ من الفنون اللغوية السابقة مادة للتدريب والتعليم، فالمفروض ألا يكتب الطالب إلا ما استمع إلياه، أو قرأ عنده، أو تحدث به..F. Marlion \& Wijayanti, 2019) وهكذا نرى أن اللغة متكامل يتأثر كل فن من فنونها بالفنون الأخرى، وأن منهج اللغة العربية ليس غاية ذاته، وإنما هو وسيلة لتحقيق غاية، وهي تعديل سلوك التلاميذ اللغوي من خلال تفاعلهم مع الخبرات والأنشطة اللغوية التي يحتوبها المنهج. مهارة الكتابة هي القدرة على 
استعمال اللغة في صورة الكتابة لإبداع آراء أو اقتراحات أو ما يخالج الضمير مع مراعاة صحة القواعد وتنظيم والكلمة واختيار الألفاظ وتنسيق الفقرات(أوريل

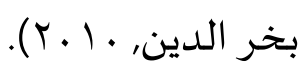

أسلوب دقيقة تخطيط بشأن أنشطة محددة لتحقيق الأهداف. أسلوبهو

تخطيط سلسلة من الأنشطة الرامية إلى تحقيق أهداف تعليمية محددة. تعيين

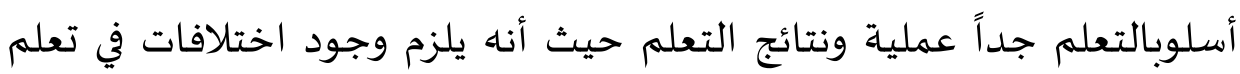
الاستراتيجيات، التي يمكن أن تساعد الطلاب على حل المشكلة. البحث عن الفكرة الرئيسية للمواد التعليمية، وبطبيعة الحال فإنه سوف تهيمن على أنشطة التعلم. وبهذه الطريقة، سوف تبدأ جو أكثر متعة حيث أنها يمكن تعظيم نتائج

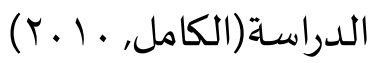

والكيفية التي يتناول بها المعلم طريقة التدريس أثناء قياماء بعملية التدريس، أو هو الأسلوب الذي يتبعه المعلم في تنفيذ طريقة التدريس بصورة تميزه عن غيره

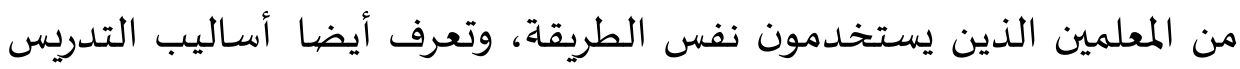
بأنها فنيات وإجراءات خاصاة يتبعها المعلم عند تنفيذه لعملية التدريس بهدف تحقيق أهداف تعليمية محددة، ومن تم فأسلوب التدريس يرتبط بصورة أساسية بالخصائص الشخصية للمعلم. وتميزه عن غيره من المعلمين. أو هي توليفة من الانماط التدريسية التي يتسم بها المعلم خلال تعامله مع الموقف التعليهي

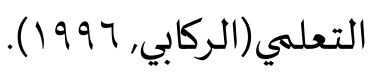
أسلوب التعلم من خلال الممارسـة يعتبر أسلوب الممارسـة والتدرب على ما تم تعلمه أفضل من أسلوب التعليم المباشر، فهذا الأسلوب يعزز الذاكرة، ويركزعلى ماسل

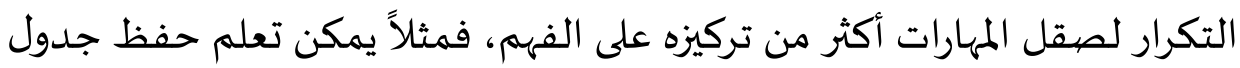

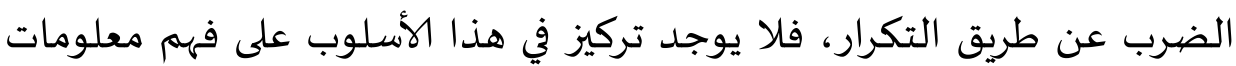

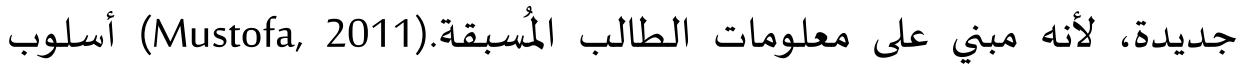
التعلم التعاوني يهدف أسلوب التعلم التعاوني إلى تقسيم الطلاب إلى مجموعات صغيرة للعمل فيها، بهدف تحقيق أهداف مشتركة، ولتحسين التحصيل الدراسي، كما أن الطالب من خلال هذا الأسلوب يتعلم تحمل المسؤولية، وكيفية العمل في مجموعات، بالإضيافة إلى اكتساباه مهارات اجتماعية متنوعة، وقد ذكر أهمية

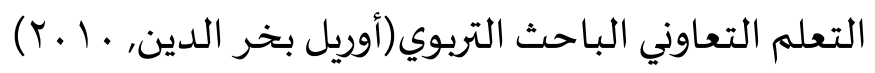


في هذا البحث سيبحث الكاتب عنتأثيرنتائج التعليم مهارة الكتابة باستعمال أسلوب ملء الحروف المفقودةفي المدرسة الثانوية عائشية بادنج. أمّا البحث في هذا الباب يتكون من خمسة فصول: صفة البيانات، امتحان شرط للتحليل، امتحان الفرضية، نتائج البحث، و حصيول البحث. مئ. بحث الكاتب عن نتيجة التلاميذ في مهارة الكلامفي الفصل التجريبي. قبل ما استخدمت المادة في مهارة الكتابة بإستخدام أسلوب ملء الحروف المفقودةفقامت الإختبار القبلي لتنظر قدرة التلاميذ على مهارة الكتابة قبل الدراسـة. بعد ذلك، قد تعلم الكاتبة مهارة الكتابة أسلوب ملء الحروف المفقودة,ثم قامت الإختبار البعدي لتنظر قدرة التلاميذ على مهارة الكتابة. ويعمل الكاتب العملية الأتية فيها: أ) التعارف بين الكاتب مع التلاميذ ب) يعطي الكاتب السؤال عن البيت إلى التلاميذ قبل أن يجرب الكاتب أسلوب الذي تصنعاء الكاتب أسلوب ملء الحروف المفقودةعلى تعليم مهارة الكتابة. ت) ثم يعمل الكاتب عملية تعليم مهارة الكتابة باستعمال أسلوب الذي تصنعها الكاتب أسلوب ملء الحروف المفقودةوباتباع خطة التعليم. ث) بعد ما تبين الكاتب مادة مهارة الكتابة عن البيت، يعطي الكاتب التمرينات إلى الى التلاميذ و وجد هذه التمرينات تقدمها الكاتب باستعمال أسلوب الذي تصنعه الكاتب أسلوب ملء الحروف المفقودة. ج) بعد ما ينتهى الكاتب أن يجرب أسلوب الذي تصنعه الكاتب أسلوب ملء الحروف المفقودة على تعليم مهارة الكتابة خصوصيا لمادة البيت، يعطي الكاتب الإستبانة إلى التلاميذ لمعرفة قدرتهم عن تعليم مهارة الكتابة باستعمال أسلوب الذي تصنعه الكاتب ملء الحروف المفقودة. ح) والأخير، يقابل الكاتب إلى المدرسـة عن مهارة الكتابة فى الصف السابع، يعني الأستاذة سوفية عن تعليم مهارة الكتابة ونتائج التلاميذ فياء باستعمال أسلوب الذي تصنعه الكاتب أسلوب ملء الحروف المفقودة. وقال الأستاذة: "أن التلاميذ يتبعون عملية التعليم جيدا وهم ينجذبون إلى أسلوب الذي تقدماه الكاتب وأن نتائج التلاميذ بعد ما يتبعون تعليم مهارة الكتابة 
باستعمال أسلوب أحسن من تعليم مهارة الكتابة بدون استعمال أسلوب

$$
\text { ملء الحروف المفقودة. }
$$

بحث الكاتب عن نتيجة التلاميذ في مهارة الكتابةفي الفصل التجريبي. قبل ما

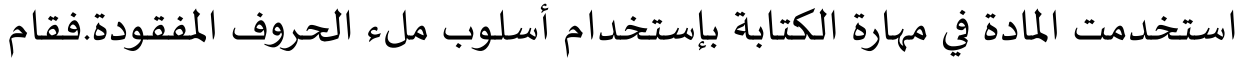

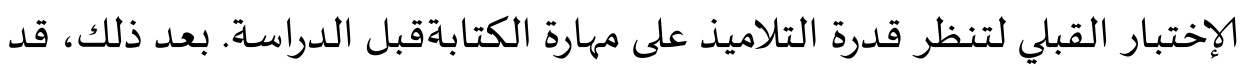
تعلم الكاتباةمهارة الكتابةبأسلوب ملء الحروف المفقودة، ثم قام الإختبار البعدي لتنظر قدرة التلاميذ على مهارة الكتابة. وفي الاختبار القبلي وجد الباحث نتيجة

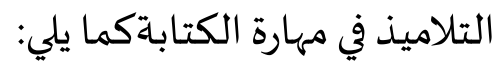

\section{الجدول الأول}

نتيجة مهارة الكتابة في الفصل التجريبي قبل استجدام أسلوب ملء الحروف المفقودة الرقم التلاميذ نتائج تعليم مهارة الكتابة معدل النتائج بأسلوب (X) (X) (x)

70,07

\begin{tabular}{|c|c|}
\hline V. & 1 \\
\hline 7. & $r$ \\
\hline V. & $r$ \\
\hline 70 & $\varepsilon$ \\
\hline 70 & 0 \\
\hline 00 & 7 \\
\hline Vo & V \\
\hline 70 & $\Lambda$ \\
\hline Vo & 9 \\
\hline 7. & 1. \\
\hline 7. & 11 \\
\hline V. & Ir \\
\hline 00 & 11 \\
\hline V. & $1 \varepsilon$ \\
\hline 70 & 10 \\
\hline 7. & 17 \\
\hline
\end{tabular}




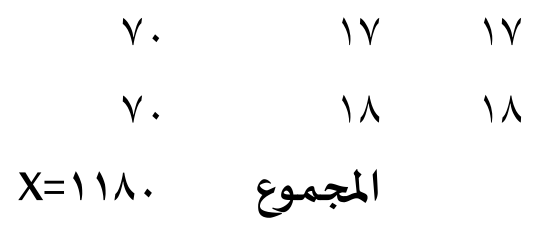

من الجدول السـابق ظهر أن كثيرا من التلاميذ لا يقدرون في مهارة الكتابة. كما رأينا يوجد نتيجة نقصان من • V فهم غير النجاح، و لتلاميذ الذين يوجد نتيجة من • V إلى أعلى فهم

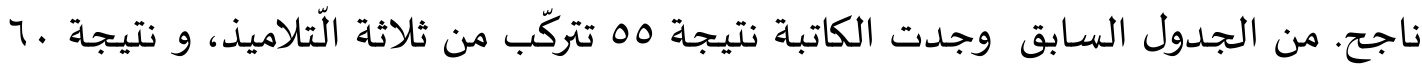

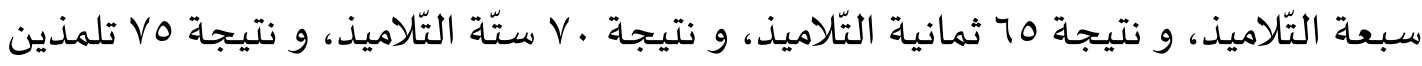
اثنين. فوجد نتيجة الأعلى قبل إستخدام أسلوب ملء الحروف المفقودة V V و نتيجة الأدنى 00

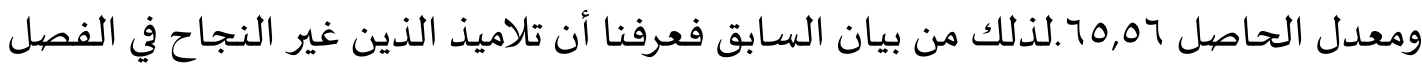
السابع ب ( الفصل التجربي ) قبل اسخدام أسلوب ملء الحروف المفقودة م \ تلاميذ، و تلاميذ الذين ناجح r تلاميذ. فهذا السرح بمعنى . 9 \% من التلاميذ غير الناجح و . 1 \% منهم ناجح. وبعد ذلك، يبحث الكاتب عن نتيجة تعليم مهارة الكتابة قبل استخدام أسلوب ملء الحروف المفقودة في الفصل التجريبي من كومبوتير باسم SPSS فيما يلي:

\section{الجـدول الثاني}

نتيجة لمهارة الكتابةقبلاستخدام أسلوب ملء الحروف المفقودة من كومبوتر

\begin{tabular}{|c|c|c|c|c|c|}
\hline \multicolumn{6}{|c|}{ Kelas Eksperimen } \\
\hline & & Frequency & Percent & Valid Percent & $\begin{array}{c}\text { Cumulative } \\
\text { Percent }\end{array}$ \\
\hline \multirow[t]{10}{*}{ Valid } & 60 & 1 & 5.6 & 5.6 & 5.6 \\
\hline & 75 & 1 & 5.6 & 5.6 & 11.1 \\
\hline & 80 & 1 & 5.6 & 5.6 & 16.7 \\
\hline & 87 & 1 & 5.6 & 5.6 & 22.2 \\
\hline & 88 & 3 & 16.7 & 16.7 & 38.9 \\
\hline & 90 & 7 & 38.9 & 38.9 & 77.8 \\
\hline & 92 & 1 & 5.6 & 5.6 & 83.3 \\
\hline & 96 & 2 & 11.1 & 11.1 & 94.4 \\
\hline & 100 & 1 & 5.6 & 5.6 & 100.0 \\
\hline & Total & 18 & 100.0 & 100.0 & \\
\hline
\end{tabular}


هكذا نتائج التلاميذ في المدرسة الثانوية عائشية على نتيجة مهارة الكتابة قبل

$$
\text { استخدام أسلوب ملء الحروف المفقودة. }
$$

و بعد جرّبت الكاتب أسلوب ملء الحروف المفقودةعلى مهارة الكتابة في تلك الفصل

$$
\text { التجريبي ثم قام الإختبار البعدي. فوجدالكاتب اسلت نتيجة كما لهروف ليلي : }
$$

\section{الجدول الثالث}

نتيجة مهارة الكتابة في الفصل التجريبي باستخدام أسلوب ملء الحروف المفقودة.

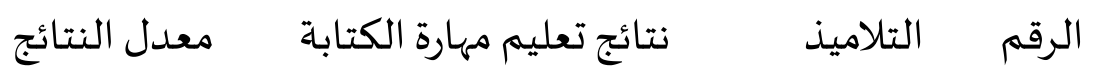

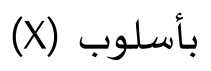

$\wedge V, V \vee$

$\begin{array}{lll}9 . & 1 & r \\ 9 r & r & r \\ 1 r & r & r \\ 9 . & \varepsilon & \varepsilon \\ 11 & 0 & 0 \\ 1 . . & 7 & 7 \\ 9 . & V & V \\ 97 & 1 & 1 \\ 97 & 9 & 9 \\ 11 & 1 . & 1\end{array}$

9.

$11 \quad 11$

$\wedge$

it it

9.

ir ir

7.

I $\quad 1 \varepsilon$

vo

$10 \quad 10$

$\wedge$.

17

17

9.

IV

IV 


$\begin{array}{lll}9 . & 11 & 11 \\ X=101 . & \end{array}$

من الجدول السـابق أن نتائجهم مرتفعة من قبل استخدامها.وجدت نتيجة . . 7 تلميذة واحدة ونتيجة هVتلميذة واحدة ونتيجة . رتلميذة واحدة و نتيجة 01خمسة تلاميذ ونتيجة

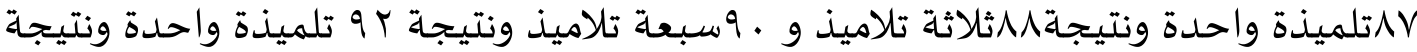
97 تلمذين اثنين ونتيجة . . ا تلميذة واحدة. من بيان السـابق وجد الكاتب نتيجة الأعلى . . 1 و نتيجة الأدنى .7 و معدل الحاصل AV.VV. و وجد VV IV تلميذ ناجحون في تعليم مهارة الكتابة و تلميذة واحدة فقط غير الناجح في تعليمها. فهذا الشرح 97 \% من التلاميذ ناجح و ع \% منهم غير الناجح.وبعد ذلك، يبحث الكاتب عن نتيجة تعليم مهارة الكتابة قبل استخدام أسلوب ملء الحروف المفقودة في الفصل التجريبي من كومبوتير باسم SPSS فيما يلي: الجدول الر ابع

نتيجة في مهارة الكتابة بعد استخدام أسلوب ملء الحروف المفقودة

Kelas Eksperimen

\begin{tabular}{|c|c|c|c|c|c|}
\hline & & Frequency & Percent & Valid Percent & $\begin{array}{c}\text { Cumulative } \\
\text { Percent }\end{array}$ \\
\hline \multirow[t]{10}{*}{ Valid } & 60 & 1 & 5.6 & 5.6 & 5.6 \\
\hline & 75 & 1 & 5.6 & 5.6 & 11.1 \\
\hline & 80 & 1 & 5.6 & 5.6 & 16.7 \\
\hline & 87 & 1 & 5.6 & 5.6 & 22.2 \\
\hline & 88 & 3 & 16.7 & 16.7 & 38.9 \\
\hline & 90 & 7 & 38.9 & 38.9 & 77.8 \\
\hline & 92 & 1 & 5.6 & 5.6 & 83.3 \\
\hline & 96 & 2 & 11.1 & 11.1 & 94.4 \\
\hline & 100 & 1 & 5.6 & 5.6 & 100.0 \\
\hline & Total & 18 & 100.0 & 100.0 & \\
\hline
\end{tabular}

هكذا نتائج التلاميذ في المدرسة الثانوية عائشية بادنج على نتيجة مهارة الكتابة بعد استخدام أسلوب ملء الحروف المفقودة. طريقة بلدون إستخدام أسلوب ملء الحرف المفقودة هي أسلوب مهاضرة هي أسلوب تستعملها المدرسـة اللغة العربية في المدرسة الثانوية عائشية بادنجفي تعليم مهارة الكتابة. في العادة المدرسة اللغة العربية تدرس التلاميذ في الفصل بهذه أسلوب. يستعمل الكاتب الإمتحان 
في الصف الضابطة لينظر نتائج تعليم مهارة الكتابة من بيان نتائج تعليم مهارة الكتابة بأسلوبمهاضرة. وجد الكاتب أقصى النتائج و و و أدنى النتائج ه广. فوجد الكاتب نتائجهم كما في جدول التالي : استخدام المدرس تلك مدرسة. و يستخدم الكاتب طريقة في الفصل المراقب بمادة سوية مع الفصل التجريبي. قبل أن يستخدماه الكاتب في الفصل المراقب بلإمتحان على التلاميذ. فوجد نتيجتهم كما يلي

\section{الجدول الخـامس}

نتيجة مهارة الكبة في الفصل المراقب قبل استخدام أسلوب مهاضرة (بدون أسلوب ملء الحروف المفقودة)

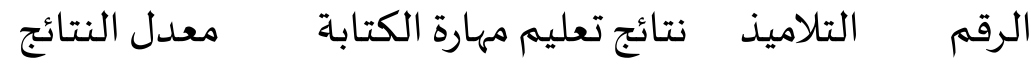

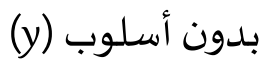

7Y.O

$\begin{array}{ccc}7 . & l & l \\ V . & r & r \\ 7 . & r & r \\ V . & \varepsilon & \varepsilon \\ 70 & 0 & 0 \\ \varepsilon r & 7 & 7 \\ V . & V & V \\ 71 & 1 & 1 \\ V . & 9 & 9 \\ r 0 & 1 . & 1 . \\ V r & 11 & 11 \\ 7 . & 1 r & 1 r \\ 71 & 1 r & 1 r \\ 7 . & 1 \varepsilon & 1 \varepsilon \\ 55 & 10 & 10 \\ 63 & 17 & 17 \\ V 0 & 1 V & 1 V\end{array}$




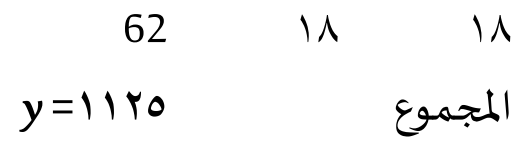

من الجدول السابق أن أكثر من التلاميذ لا يقدرون في مهارة الكتابة ـ من الجدول السـابق وجدنا نتيجة هب تلميذا واحدا، ونتيجة بع تلميذا واحدا ، ونتيجة 00 تلميذا واحدا، ونتيجة . 7 أربعة التّلاميذ، ونتيجة با 7 تلميذا واحدا، ونتيجة سج تلميذا واحدا ونتيجة 70 تلميذ واحد ونتيجة 1 ي تلميذ واحد، ونتيجة . V أربعة التلاميذ واحد ونتيجة V0 تلميذ واحد. فوجد الكاتب

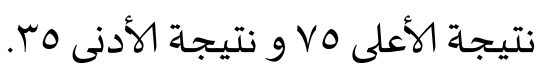

من بيانت السابق فعرفنا أن التّلاميذ الذين غير الناجح في الصل السابع أ (الفصل المراقب) قبل استخدام أسلوب مهاضرة (بدون أسلوب ملء الحروف المفقودة) \1 التلاميذ ، و التلاميذ الذين ناجح ا التلاميذ. فهذا الشرح بمعنى 9\% من التلاميذ غير ناجح و ه \% منهم

وبعد ذلك يبحث الكاتب عن النتيجة التعليم مهارة الكتابة قبل استخدام أسلوب ملء الحروف المفقودة (بدون أسلوب ملء الحروف المفقودة) في الفصل المراقب من كومبوتر بالسم : SPSS

\section{الجدول السـادسية}

نتيجة مهارة الكتابة في الفصل المراقب قبل استخدام أسلوب المهاضرة (بدون أسلوب ملء

$$
\text { الحروف المفقودة) من كومبوتر }
$$

\section{KelasKontrol}

\begin{tabular}{|c|c|c|c|c|c|}
\hline \multicolumn{1}{|c|}{ Valid } & 60 & 1 & 5.6 & 5.6 & 5.6 \\
& 65 & 3 & 16.7 & 16.7 & 22.2 \\
& 70 & 9 & 50.0 & 50.0 & 72.2 \\
& 72 & 1 & 5.6 & 5.6 & 77.8 \\
& 75 & 2 & 11.1 & 11.1 & 88.9 \\
& 79 & 1 & 5.6 & 5.6 & 94.4 \\
& 80 & 1 & 5.6 & 5.6 & 100.0 \\
& Total & 18 & 100.0 & 100.0 & \\
\hline
\end{tabular}

هكذا نتئج التلاميذ في المدرسـة الثانوية عائشيّة بادنج على نتيجة مهارة الكتابة قبل استخدام أسلوب المهاضرة (بدون أسلوب ملء الحروف المفقودة) وبعدما استخدام الكاتب 
أسلوب المهاضرة على مهارة الكتابة في تلك الفصل المراقب فيقوم الكاتب بالإمتحان على التلاميذ. فوجد الكاتب النتيجة كما يلي :

\section{الجدول السابع}

نتيجة مهارة الكتابة في الفصل مراقب بإستخدام أسلوب المهاضرة (بدون أسلوب ملء الحروف المفقودة) الرقم التلاميذ نتائج تعليم مهارة الكتابة بدون معدل النتائج

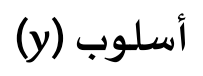

VT,AT

$\begin{array}{ccc}70 & l & l \\ 70 & r & r \\ V . & r & r \\ V . & \varepsilon & \varepsilon \\ V 0 & 0 & 0 \\ V 9 & 7 & 7 \\ V 0 & V & V \\ V . & 1 & 1 \\ 7 . & 9 & 9 \\ V 0 & 1 . & 1 . \\ V r & 11 & 11 \\ V . & 1 r & 1 r \\ V . & 1 r & 1 r \\ 70 & 1 \varepsilon & 1 \varepsilon \\ V . & 10 & 10 \\ V 0 & 17 & 17 \\ V . & 1 V & 17 \\ V . & 11 & 11 \\ y=1 r & & \varepsilon a r l\end{array}$

هكذا نتائج التلاميذ بعد استخدام أسلوب مهاضرة (بدون أسلوب ملء الحروف المفقودة) على مهارة الكتابة. فنظرنا من الجدول السابق أن نتائجهم مرتفة قليلة من قبل استخدافها التها. 
ونتيجة .7 تلميذ واحد، ونتيجة 70 ثلاثة التلاميذ، ونتيجة . V0 تسعة التلاميذ، ونتيجة أربعة التلميذ، ونتيجة V9 تلميذ واحد. من بيان السابق وجدنا نتيجة الأعلى V9 و نتيجـة الأدنى هr ومعدل الحاصل سr. . V. ووجد ه تلاميذ ناجحون في تعليم مهارة الكتابة و با تلاميذ غير ناجحون في تعليمها. فهذا الشرح بمعنى حس\% من التلاميذ ناجح و \&7\% منهم غير ناجح. بحث الكاتب عن النتيجة تعليم مهارة الكتابة باستخدام أسلوب المهاضرة (بدون أسلوب ملء الحروف المفقودة) في الفصل المراقب من كومبوتر بالسم SPSS فيما يلي :

$$
\text { الجدول العشر }
$$

$$
\text { نتيجة مهارة الكتابة في الفصل مراقب بإستخدام أسلوب المهاضرة (بدون أسلوب ملء الحرول }
$$

\begin{tabular}{|c|l|l|l|l|l|}
\hline & & & & & KelasKontrol \\
& & Frequency & Percent & Valid Percent & $\begin{array}{l}\text { Pumulative } \\
\text { Percent }\end{array}$ \\
\hline Valid & 60 & 1 & 5.6 & 5.6 & 5.6 \\
& 65 & 3 & 16.7 & 16.7 & 22.2 \\
70 & 9 & 50.0 & 50.0 & 72.2 \\
72 & 1 & 5.6 & 5.6 & 77.8 \\
75 & 2 & 11.1 & 11.1 & 88.9 \\
79 & 1 & 5.6 & 5.6 & 94.4 \\
80 & 1 & 5.6 & 5.6 & 100.0 \\
Total & 18 & 100.0 & 100.0 & \\
\hline
\end{tabular}

هكذا نتائج التلاميذ في المدرسة الثانوية عائشية بادنج على نتيجة مهارة الكتابة

$$
\text { باستخدام أسلوب المهاضرة ( بدون أسلوب ملء الحروف المفقودة). }
$$

من نتائج التعليم في الفصل التجريبي و الفصل المراقب، وجدنا اختلاف في معدل النتيجة. أما معدل النتيجة في الفصل لمراقب قبل Tr,0 و بعد سب,NT، و و في الفصل التجريبي قبل 10,01 و و بعد و معدل النتيجة أعلى الفصل التجريبي 70,VV، 70 من الفصل المراقب،

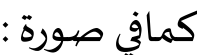




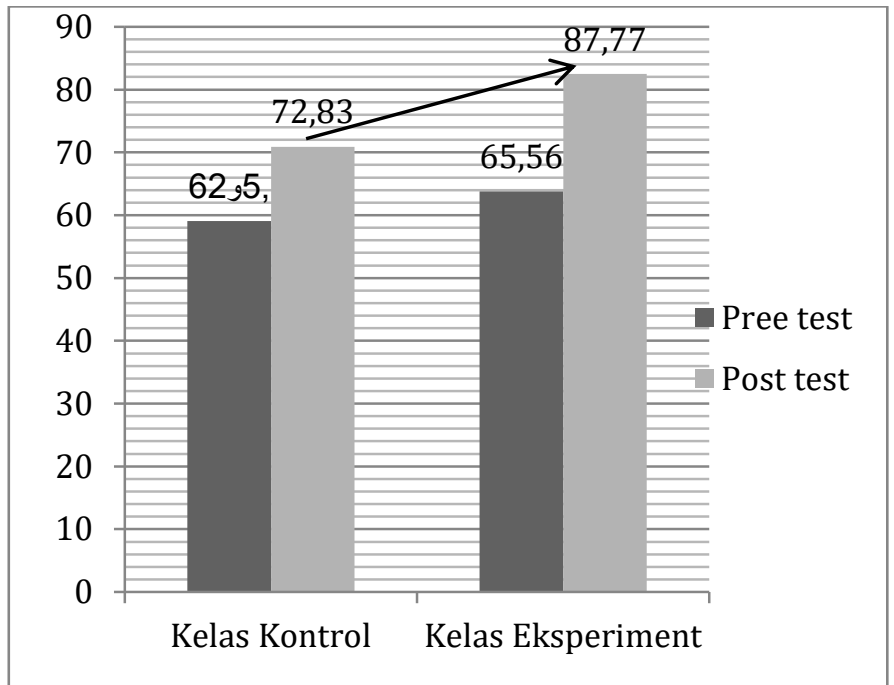

\section{امتحان لشرط التحليل}

قبل أن يستعمل الكاتب امتحان الفرضاة يحتاج فحص بيانات لمتغيرات Xو Y. وفي هذا الفحص يعمل الكاتب الإمتحان نورمالتس (Uji Normalitas)و الإمتحان هموجنيهس( Uji .(Homogenitas

أمّا الغرض من امتحانين هو لتأخذ الخلاصة بصحيحة و تمام يستعمل الكاتب امتحان نورمالتس بالإمتحان ليليفورس الإمتحان هموجنيتس بالإمتحان بارتليت(Bartlett). امتحان نورمالتس يستعمل الكاتب امتحان نورمالتس البيانات بكيفية امتحان ليلفور (Liliefors)معرفة نورمالأو غير نورمال من الإمتحان يستعمل الكاتبفي إعطائه إلى عينة البحث، فتحلل الكاتب

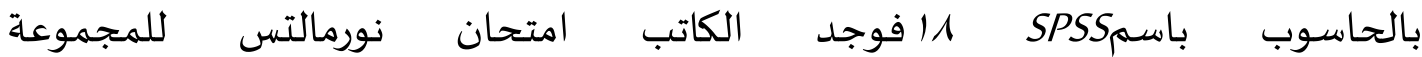

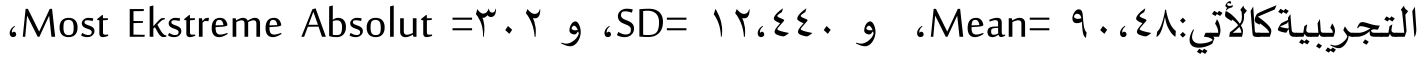
1,383Kolmogorof- g،-•,r.r $=$ Differences Negatifg Differences Positif= ) X و و-2mirnov Z= نتائج تعليم مهارة الكتابة باستعمال أسلوب ملء الحروف المفقودة. وما أصبح ذلك، لمعرفة نورمالأو غير نورمال من الإمتحان يستعمل الكاتب في إعطاء الإمتحان إلى العينة البحث، فتحلل الكاتب بالحاسوب باسميSPSSفوجدالكاتب امتحان

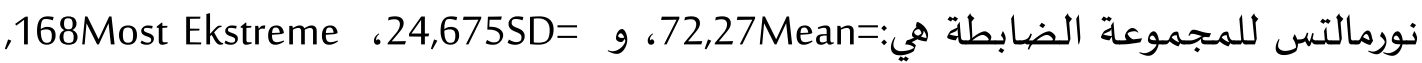
-,168DifferencesNegatif=, •و،,135Differences Positif $=$ ، Absolut 
، و 561 tailedAsymp. Sig. (2-9,790Kolmogorof-Smirnov Z, وهكذا حاصل الإمتحان

$$
\text { نورمالتس في متغيرY فظهر حاصل في الجدول: }
$$

One-Sample Kolmogorov-Smirnov Test

\begin{tabular}{|ll|l|l|}
\hline & & Kelas Eksperimen & KelasKontrol \\
\hline Normal Parameters & & & \\
& & & \\
& & & \\
Most Extreme Differences & Std. Deviation & 8.855 & 18 \\
& Absolute & .298 & 70.33 \\
& Positive & .179 & 4.899 \\
251 \\
Test Statistic & Negative & -.298 & .249 \\
Asymp. Sig. (2-tailed) & & .298 & .251 \\
& & $.000^{c}$ & $.004^{c}$ \\
\hline
\end{tabular}

a. Test distribution is Normal.

b. Calculated from data.

c. Lilliefors Significance Correction.

من الجدوال السـابق ظهر أن الفرقة في هذه البحث أصلاه من العينة نورمال، لذلك شرط

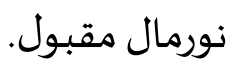

$$
\text { امتحان هموجنيتس }
$$

امتحان هموجنيتس على فرقة باستعمال أسلوب بارت ليت (Barlett). لمعرفة هموجنيتسأو

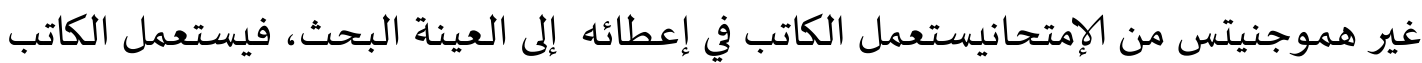

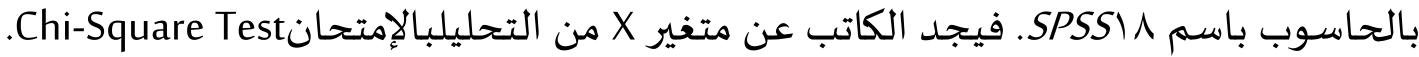

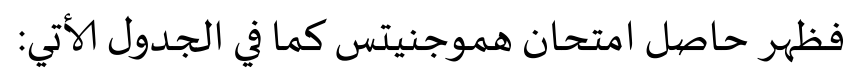

\section{الجدول اثناعشـة}

جدول Chi-Square Test المجموعة التجربية)

\section{Kelas Eksperimen}

\begin{tabular}{|l|l|l|l|}
\hline & Observed N & Expected N & Residual \\
\hline 60 & 1 & 2.0 & -1.0 \\
75 & 1 & 2.0 & -1.0
\end{tabular}




\begin{tabular}{|l|l|l|l|}
80 & 1 & 2.0 & -1.0 \\
87 & 1 & 2.0 & -1.0 \\
88 & 3 & 2.0 & 1.0 \\
90 & 7 & 2.0 & 5.0 \\
92 & 1 & 2.0 & -1.0 \\
96 & 2 & 2.0 & 0 \\
100 & 1 & 2.0 & -1.0 \\
Total & 18 & & \\
\hline
\end{tabular}

\section{وما أصبح ذلك،في متغير Yقام الكاتب الإمتحان هموجنيتس بالإمتحان Chi-Square Test،

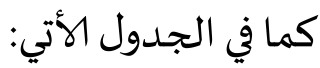

\section{الجدوال ثلاثة العشر}

جدول) المجمموعة الضابطة (Y)

\begin{tabular}{|l|l|l|l|}
\hline \multicolumn{5}{|c|}{ KelasKontrol } \\
\hline 60 & Observed N & Expected N & Residual \\
65 & 3 & 2.6 & -1.6 \\
70 & 9 & 2.6 & .4 \\
72 & 1 & 2.6 & 6.4 \\
75 & 2 & 2.6 & -1.6 \\
79 & 1 & 2.6 & -.6 \\
80 & 1 & 2.6 & -1.6 \\
Total & 18 & 2.6 & -1.6 \\
\hline
\end{tabular}

الجدوال أربعة العشي

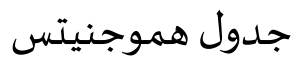

\begin{tabular}{|l|l|l|}
\hline \multicolumn{3}{c|}{ Test Statistics } \\
\hline & Kelas Eksperimen & KelasKontrol \\
\hline Chi-Square & $16.000^{\mathrm{a}}$ & $20.111^{\mathrm{b}}$ \\
Df & 8 & 6 \\
Asymp. Sig. & .042 & .003 \\
\hline
\end{tabular}

a. 9 cells $(100.0 \%)$ have expected frequencies less

than 5 . The minimum expected cell frequency is 2.0 . 


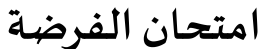

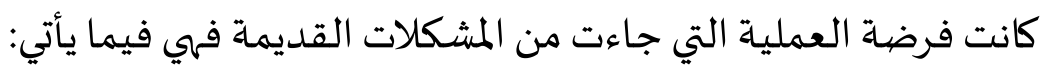

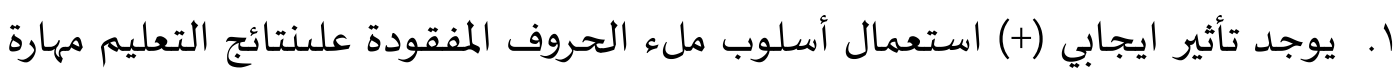
الكتابة في المدرسة الثانوية عائشية بادنج (Ha).

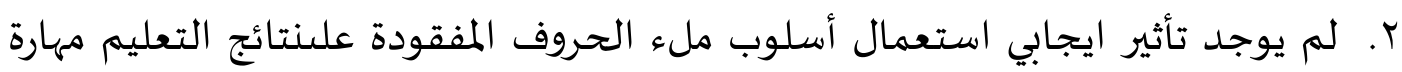
الكتابة في المدرسة الثانوية عائشية بادنج (Ho).

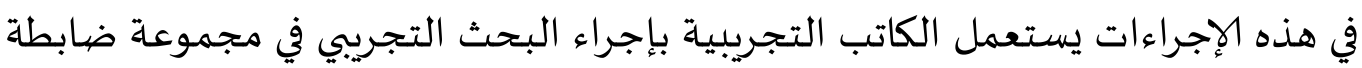

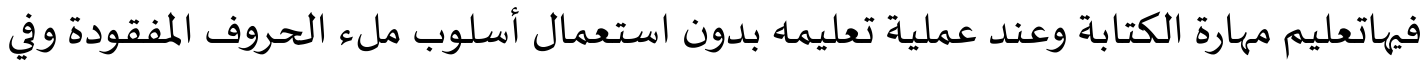

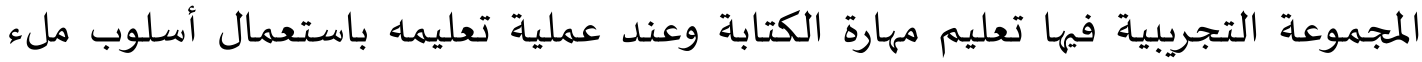

$$
\text { الحروف المفقودة. }
$$

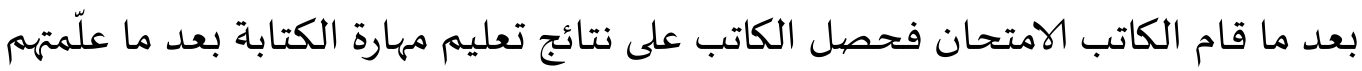

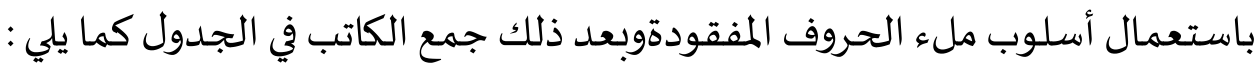

$$
\begin{aligned}
& \text { الجدوال خمسية العشي }
\end{aligned}
$$

\begin{tabular}{|c|c|c|c|c|c|}
\hline$D^{2}$ & $D=(X-Y)$ & $\mathrm{Y}$ & $x$ & التلاميذ & الرقم \\
\hline Tro & To & 70 & 9. & 1 & 1 \\
\hline VYq & $T V$ & 70 & $q r$ & $r$ & $r$ \\
\hline rAq & IV & V. & AV & $r$ & $r$ \\
\hline$\varepsilon \ldots$ & $r$. & V. & $q$. & $\varepsilon$ & $\varepsilon$ \\
\hline ru.q & or & ro & 从 & 0 & 0 \\
\hline$\varepsilon \varepsilon 1$ & rI & 19 & $1 \ldots$ & 7 & 7 \\
\hline$\varepsilon \ldots$ & $r$. & V. & 9. & V & V \\
\hline 787 & r & V. & 97 & 1 & 1 \\
\hline $1 Y 97$ & rq & 7. & 97 & 9 & 9 \\
\hline 179 & $1 \pi$ & Vo & $\Lambda \Lambda$ & 1. & . \\
\hline
\end{tabular}

نتائج التعليم من المجموعة التجريبية والمجموعة الضابطة 


\begin{tabular}{|c|c|c|c|c|}
\hline TYE & 11 & VT & 9. & 11 \\
\hline TrE & 11 & V. & $\Lambda \Lambda$ & IT \\
\hline$\varepsilon \ldots$ & $r$. & V. & 9. & س \\
\hline ro & -0 & 70 & 7. & $1 \varepsilon$ \\
\hline ro & 0 & V. & Vo & 10 \\
\hline ro & 0 & Vo & $\wedge$. & 17 \\
\hline$\varepsilon \ldots$ & $r$. & V. & 9. & IV \\
\hline$\varepsilon \ldots$ & $r$. & V. & 9. & 11 \\
\hline$\sum D^{2}=$ & $\sum D=$ & $\sum Y=$ & 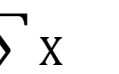 & \\
\hline V.IT & Mlع & 1577 & $=1580$ & \\
\hline
\end{tabular}

وفي إنتهاء البيانات السابقات استعمل الكاتب الرمز t test فيما يلي:

$$
\begin{aligned}
& t_{o}=\frac{M_{D}}{S E_{M D}} \\
& \text { وأما خطوات إحصائيتها فهي ما يلي: }
\end{aligned}
$$

ا ل. يبحث الكاتب عن تفريق بين النتيجتين باستعمال الرمز D=X-Y

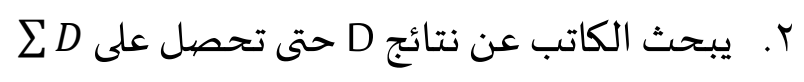

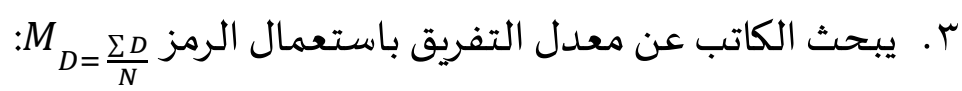

$$
\begin{aligned}
M_{D} & =\frac{\sum D}{N} \\
& =\frac{314}{18}=1 \mathrm{~V}, \leqslant \leqslant
\end{aligned}
$$

ع. يضاعف الكاتب نتائج التفريق D تم يبلغها حتى تحصل نتائج

ه. يبحث الكاتب عن Defiasi Standar dari Diference (SDD) باستعمال

$$
\begin{gathered}
S D_{D}=\sqrt{\frac{\sum D^{2}}{N}}-\frac{\left(\sum D\right)^{2}}{N}: \text { الرمز } \\
S D_{D}=\sqrt{\frac{\sum D^{2}}{N}-\frac{\left(\sum D\right)^{2}}{N}} \\
S D_{D}=\sqrt{\frac{7012}{18}-\frac{(314)^{2}}{18}} \\
=\sqrt{85,41}=9,24 S D_{D}=\sqrt{389,56}-304,15
\end{gathered}
$$


T.

$$
\begin{gathered}
S E_{M_{D}}=\frac{S D_{D}}{\sqrt{N-1}}: \text { الرمز } \\
S E_{M_{D}}=\frac{S D_{D}}{\sqrt{N-1}} \\
S E_{M_{D}}=\frac{9,24}{\sqrt{18-1}} \\
S E_{M_{D}}=\frac{9,24}{\sqrt{17}} \\
S E_{M_{D}}=\frac{9,24}{4,12} \\
S E_{M_{D}}=2,24
\end{gathered}
$$

\begin{tabular}{|c|c|c|c|c|c|}
\hline \multicolumn{6}{|c|}{ Test Value $=0$} \\
\hline \multirow[b]{2}{*}{$\mathrm{T}$} & \multirow[b]{2}{*}{$\mathrm{df}$} & \multirow{2}{*}{$\begin{array}{l}\text { Sig. (2- } \\
\text { tailed) }\end{array}$} & \multirow{2}{*}{$\begin{array}{l}\text { Mean } \\
\text { Difference }\end{array}$} & \multicolumn{2}{|c|}{$\begin{array}{l}95 \% \text { Confidence } \\
\text { Interval of the } \\
\text { Difference }\end{array}$} \\
\hline & & & & Lower & Upper \\
\hline
\end{tabular}

$$
\begin{aligned}
& t_{o}=\frac{M_{D}}{S E_{M_{D}}}: \text { يبحث الكاتب عن to t } \\
& t_{o}=\frac{M_{D}}{S E_{M_{D}}} \\
& t_{o}=\frac{17,44}{2,24} \\
& t_{o}=7,79 \\
& \text { أما نتائج تحليل من الحاسوب فيما يلي : } \\
& \text { الجدول السادسة العشر }
\end{aligned}
$$

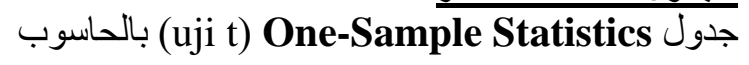

One-Sample Statistics

\begin{tabular}{|l|l|l|l|l|}
\hline & N & Mean & $\begin{array}{l}\text { Std. } \\
\text { Deviation }\end{array}$ & $\begin{array}{l}\text { Std. Error } \\
\text { Mean }\end{array}$ \\
\hline Kelas & 18 & 87.78 & 8.855 & 2.087 \\
Eksperimen & 18 & 70.33 & 4.899 & 1.155 \\
KelasKontrol & 18 & \\
\hline
\end{tabular}

جذولOne-Sample Test الجدول السابعة عشر

\section{One-Sample Test}


تأثير أسلوب ملء الحروف المفقودة على مهارةالكتاب

\begin{tabular}{|c|c|c|c|c|c|c|}
\hline $\begin{array}{l}\text { Kelas } \\
\text { Eksperimen } \\
\text { KelasKontrol }\end{array}$ & $\begin{array}{l}42.05 \\
4 \\
60.91 \\
0\end{array}$ & $\begin{array}{l}17 \\
17\end{array}$ & $\begin{array}{l}.000 \\
.000\end{array}$ & $\begin{array}{l}87.778 \\
70.333\end{array}$ & $\begin{array}{l}83.37 \\
67.90\end{array}$ & $\begin{array}{l}92.18 \\
72.77\end{array}$ \\
\hline
\end{tabular}

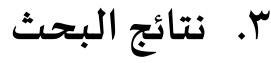

بناء على أسئلة البحث في منهج البحث فتفسر الكاتب نتائج to وt بالشرط كما يلي،

فترمز الكاتب الفرضية كما يلي :

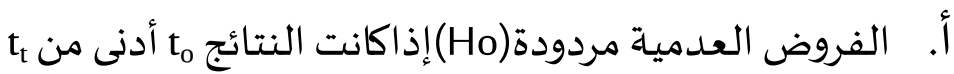

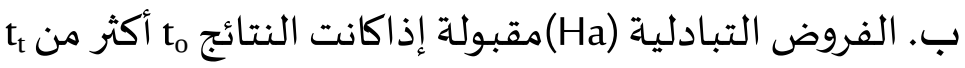

بعد ما حلل الكاتب هذه البيانات التيتتعلم بالرمز test فحصل الكاتب نتائجr,or.r.

وبعد ذلك بحث الكاتب عنdegreeoffreedom)df الذين يتعلمون بالرمز df = n-1 قبل

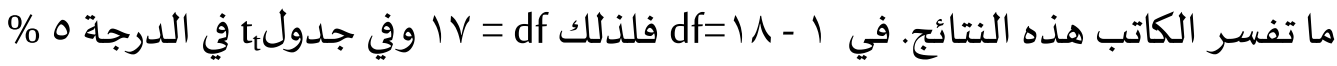

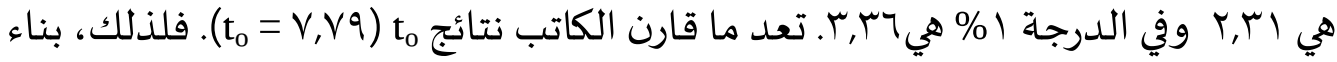
على البيانات السـابقة فعلم الكاتب أن نتائج t أكبر من نتائج th كما يلي:

$r, r)<V, V q>r, r q$

ج .الخلاصة

ومن الحصول انتهاء الرمز السـابقة أخذ الكاتب نتائج to أكبر من نتائج to فالفروض العدميةHo مردودة والفروض التبادلية Haمقبولة، المراد بها أن هناك اختلاف بين نتائج الامتحان الأول. بعدما رأى الكاتب من نتائج امتحان الفرضية السابق فيخلص كاتب أهنا يوجد فرق بين قدرة التلاميذ في تعليم مهارة الكتابة استعمال أسلوب ملء الحروف المفقودة وبدون استعمال أسلوب ملء الحروف المفقودة. تعليم المهارة الكتابة في المدرسة الثانوية عائشية بادنج بطريقة المهاضرة. رأى الكاتب نتائجتهم في تعليم مهارة الكتابة كثير أدنى الحصولية المنخفضية (V0) ثم الكاتب تجريبي باستعمال أسلوب ملء الحروف المفقودةكثيرنتائجتهم أعلى الحصولية المنخفضة. والخلاصة في هذا البحث هي أن الأسلوب ملء الحروف المفقودةمتغيرXيستطيعأنيؤثر تعليم المهارة الكتابة هناك تأثير الإجابي في المدرسـة الثانوية عائشياة بادنج. بناء على نتائج البحث في الباب الرابع السـابق، فيأخذ الكاتب الخلاصة لهذه الرسالة العلمية أن أسلوب ملء الحروف المفقودة، يؤثر تأثيرا إيجابيا على نتائج تعليم مهارة 
الكتابة في الصف السابع من المدرسة الثانوية عائشية بادنج. كما بين الكاتب فيما يلي: النتائج

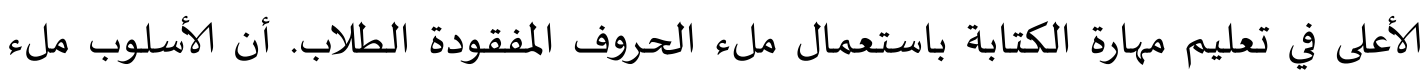

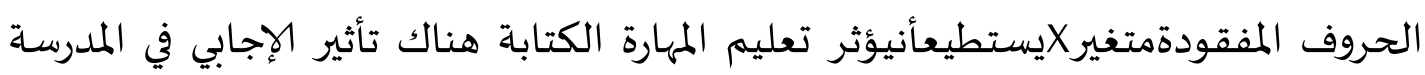
الثانوية عائشية بادنج. 


\section{المراجع}

Asrori, I. (2010). Aneka Permainan Penyegar Pembelajaran Bahasa Arab (p. 86). Hilal Pustaka.

Marlion, F. (2017). Metode pendidikan dipelajari dari metode bijak dalam AlQuran.

Marlion, F. A. (2019). أسلوب الحكيم في القرآن الكريم: دراسة تحليلية بلاغية. In lughawiyah (Vol. 1, Issue 2).

Marlion, F., \& Wijayanti, T. (2019). Makna Ayat-ayat Perumpamaan Di Dalam Surat Ali Imran. An-Nida', 43(2), 1-19.

Mustofa, S. (2011). Strategi Pembelajaran Bahasa Arab Inovatif. UIN-Maliki Press.

أوريل بخر الدين. ( . . (Y).تطوير منهج تعليم اللغة العبرية وتطبيقة على مهارة الكتابة. مطبعة

الجامعة.

الركابي, ج. (1997). طرق تعليم اللغة العربية. دار الفكر المعاصر.

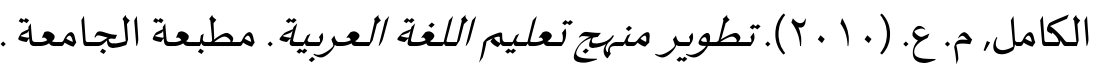

شحاتة, ح. (797 (199).تعليم اللغنة العربية بين النظرية و التطبيق. الحار العربية اللبنانية. 